\title{
Direct evidence that the N-terminal extensions of the TAP complex act as autonomous interaction scaffolds for the assembly of the MHC I peptide-loading complex
}

\author{
Sabine Hulpke • Maiko Tomioka • Elisabeth Kremmer • \\ Kazumitsu Ueda $\cdot$ Rupert Abele $\cdot$ Robert Tampé
}

Received: 26 February 2012/Revised: 18 April 2012/Accepted: 20 April 2012/Published online: 27 May 2012

(C) The Author(s) 2012. This article is published with open access at Springerlink.com

\begin{abstract}
The loading of antigenic peptides onto major histocompatibility complex class I (MHC I) molecules is an essential step in the adaptive immune response against virally or malignantly transformed cells. The ER-resident peptide-loading complex (PLC) consists of the transporter associated with antigen processing (TAP1 and TAP2), assembled with the auxiliary factors tapasin and MHC I. Here, we demonstrated that the N-terminal extension of each TAP subunit represents an autonomous domain, named $\mathrm{TMD}_{0}$, which is correctly targeted to and inserted into the ER membrane. In the absence of coreTAP, each $\mathrm{TMD}_{0}$ recruits tapasin in a 1:1 stoichiometry. Although the $\mathrm{TMD}_{0}$ s lack known ER retention/retrieval signals, they are localized to the ER membrane even in tapasin-deficient cells. We conclude that the $\mathrm{TMD}_{0} \mathrm{~s}$ of TAP form autonomous interaction hubs linking antigen translocation into the ER with peptide loading onto MHC I, hence ensuring a major function in the integrity of the antigen-processing machinery.
\end{abstract}

S. Hulpke $\cdot$ R. Abele $\cdot$ R. Tampé $(\bowtie)$

Biocenter, Institute of Biochemistry and Cluster of Excellence Frankfurt (CEF) - Macromolecular Complexes,

Goethe-University Frankfurt, Max-von-Laue-Str. 9, 60438 Frankfurt am Main, Germany

e-mail: tampe@em.uni-frankfurt.de

\section{Tomioka $\cdot$ K. Ueda}

Laboratory of Cellular Biochemistry, Division of Applied Life Sciences, Graduate School of Agriculture and Institute for Integrated Cell-Material Sciences (iCeMS), Kyoto University, Kyoto 606-8502, Japan

\section{E. Kremmer}

Helmholtz-Center Munich, German Research Center for Environmental Health, Institute of Molecular Immunology, Marchioninistr. 25, 81377 Munich, Germany
Keywords ABC transporter - Antigen processing . Membrane protein interaction $\cdot$ Macromolecular membrane complex $\cdot$ Tapasin
Abbreviations
Crt Calreticulin
ER Endoplasmic reticulum
ERGIC ER-Golgi intermediate compartment
MHC I Major histocompatibility complex class I
PLC Peptide-loading complex
TAP Transporter associated with antigen processing
TMD Transmembrane domain
Tsn Tapasin
wt Wild-type

\section{Introduction}

The adaptive immune system of jawed vertebrates is responsible for detection and elimination of virus-infected or malignantly transformed cells, thus playing an essential role in survival. Information about the cellular proteome is presented to cytotoxic $\mathrm{T}$ cells on the cell surface in the form of complexes of MHC I molecules with antigenic peptides derived from intracellular proteins [1-3]. A large portion of the cellular proteome is degraded by the proteasome. A fraction of these antigenic peptides is transported into the lumen of the endoplasmic reticulum (ER) by the transporter associated with antigen processing (TAP), a heterodimeric ABC complex composed of TAP1 (ABCB2) and TAP2 (ABCB3). The loading of peptides onto MHC I takes place within the peptide-loading complex (PLC), a multisubunit machinery consisting of TAP1/2, MHC I heavy chain $/ \beta_{2}$-microglobulin, the chaperone 
calreticulin, the oxidoreductase ERp57, and tapasin (Tsn). The latter is an essential adapter molecule within the PLC, as it bridges the peptide donor (TAP) with the peptide acceptor (MHC I) [4, 5]. For a large number of MHC I alleles, tapasin is required for loading of high-affinity peptides onto MHC I, a process known as peptide editing $[6,7]$. After loading their peptide cargo, MHC I complexes travel via the secretory pathway to the cell surface. Large efforts have been made to understand the assembly, organization, and function of the PLC. For most ER-lumenal parts, structural information is available [8-12]. However, TAP cannot yet be crystallized, and only a homology model of the coreTAP complex is available based on the X-ray structures of bacterial ABC transporter Sav1866 and the NBD1 of TAP1 [13-15].

Each coreTAP subunit consists of six transmembrane helices plus the nucleotide-binding domain. CoreTAP shares significant homology with other $\mathrm{ABC}$ transporters and is necessary and sufficient for peptide binding and transport [16]. In contrast, the unique $\mathrm{N}$-terminal domain with four putative transmembrane-spanning segments, called $\mathrm{TMD}_{0}$, shares no homology to any other known protein. Deletion of the first transmembrane-spanning segment of TAP destroys its ability to interact with tapasin [17]. However, there is no structural information available for the $\mathrm{TMD}_{0}$ of TAP1 and TAP2. Despite their critical role in PLC assembly, the $\mathrm{TMD}_{0} \mathrm{~s}$ constitute the least understood part of this macromolecular machinery. $\mathrm{TMD}_{0}$ of TAP2 (hereafter named $\mathrm{TMD}_{0}^{\mathrm{TAP} 2}$ ) is about 30 amino acids shorter than that of TAP1 $\left(\mathrm{TMD}_{0}^{\mathrm{TAP} 1}\right)$. Although their sequences markedly differ, both $\mathrm{TMD}_{0} \mathrm{~s}$ seem to fulfill similar functions in tapasin binding [16], in spite of data indicating a functional asymmetry of greater significance of the rat $\mathrm{TMD}_{0}^{\mathrm{TAP} 2}$ in PLC function [18]. In this study, the functionality and structural integrity of the $\mathrm{TMD}_{0} \mathrm{~s}$ of both TAP subunits were addressed with regard to their subcellular localization, binding, and stoichiometry of tapasin.

\section{Materials and methods}

\section{Cloning and constructs}

$\mathrm{TMD}_{0}^{\mathrm{TAP} 1}$ and $\mathrm{TMD}_{0}{ }^{\mathrm{TAP} 2}$ were cloned into pcDNA3.1(+) (Invitrogen, Darmstadt, Germany) via XhoI/EcoRI and KpnI/NotI, respectively. To generate $\mathrm{TMD}_{0}^{\mathrm{TAP} 1}$ (aa 1-164 of TAP1) with a C-terminal myc-tag and $\mathrm{TMD}_{0}^{\mathrm{TAP} 2}$ (aa 1-127 of TAP2) with a C-terminal HA-tag, the following primer pairs were used: 5'-GTCGACGAATTCATGGC TAGCTCTAGGTG- $3^{\prime}$ and $5^{\prime}$-GTCGACCTCGAGTCACA GATCCTCTTCTGAGATGAGTTTTTGTTCGGATCCG CCGGGCACCCAG-3' $3^{\prime}$ for TMD $_{0}^{\mathrm{TAP} 1}$, 5'-GTCGACGG TACCAGATCTACCATGCGGCTCCCTGACCTG- $3^{\prime}$ and
5'-GTCGACGCGGCCGCTCAAGCGTAGTCTGGGACG TCGTATGGGTAGGATCCCTTCTCCTGGGCTCC- ${ }^{\prime}$ for $\mathrm{TMD}_{0}^{\mathrm{TAP} 2}$. CoreTAP1 (amino acids 165-748, containing an N-terminal methionine) was amplified with primer pairs $5^{\prime}$-CGATTACTCGAGATGGGTCAGGGCGGCTC- ${ }^{\prime}$ and $5^{\prime}$-CGATTAGAATTCCCTTCTGGAGCATCTGC- $3^{\prime}$ and cloned into pEGFP-N3 (BD Biosciences, Franklin Lakes, NJ, USA) via XhoI and EcoRI sites. CoreTAP2-mCerulean (amino acids $125-716$ plus $\mathrm{N}$-terminal methionine) containing a C-terminal StrepII-tag was amplified with the primer pair 5'-CATGCTTAAGATGGCCCAGGAGAAGG AGCAGGACC-3' and 5'-CCGCTCGAGTCACTTCTCGA ATTGTGGGTGAGACCAAGC- $3^{\prime}$, then cloned into pcDNA3.1(+) via AflII and XhoI. Tsn-TMD ${ }_{0}$ constructs were amplified via PCR with the following primers: $5^{\prime}-\mathrm{AG}$ ATCTATGAAGTCCCTGTCTCTGCTCCTCG $-3^{\prime}$ as forward primer for both constructs, 5'-ATCGCGGCCGCT CACAGATCCTCTTCTGAGATGAGTTTTTGTTCACC TCCAGGCACCCAAAGACTACC- $3^{\prime}$ for Tsn-TMD ${ }_{0}^{\mathrm{TAP} 1}$ containing a C-terminal myc-tag and $5^{\prime}$-GTCGACGCGGC CGCTCAAGCGTAGTCTGGGACGTCGTATGGGTAG GATCCTTTTTCTTGGGCACCTGGTGGAC- $3^{\prime}$ for Tsn$\mathrm{TMD}_{0}^{\mathrm{TAP} 2}$ with a C-terminal HA-tag. A 34 amino acid long flexible glycine-serine linker was inserted between the C-terminus of tapasin and the N-terminus of the $\mathrm{TMD}_{0}$. Both constructs were cloned into pcDNA3.1(+) via BamHI/NotI. For the TAP1/TAP2 coexpression plasmid, TAP1 was cloned into the MCS2 of pVitro2-neo-mcs (Invivogen, San Diego, CA, USA) via BglII and NheI, TAP2 was cloned into MCS1 via BamHI and SalI.

\section{Cell lines and transfection}

HeLa cells were cultured in DMEM (PAA Laboratories, Pasching, Austria) supplemented with $10 \%$ fetal calf serum (FCS; Biochrom, Berlin, Germany). M553, a human tapasin-deficient melanoma cell line [19, 20], was maintained in RPMI 1640 with $10 \%$ FCS. Transfection of M553 was performed using XtremeGene HP (Roche, Grenzach-Wyhlen, Germany) according to the manufacturer's instructions. HeLa cells were transfected with $18 \mathrm{mM}$ branched polyethyleneimine (PEI) with a DNA-toPEI ratio of one to three. After $24-48 \mathrm{~h}$, cells were harvested and used for the indicated experiments.

\section{Antibodies}

For immunofluorescence experiments, the following antibodies were used: mouse anti-myc 4A6 (Millipore, Billerica, MA, USA), mouse anti-HA HA-7 (Abcam, Cambridge, UK), mouse anti-TAP1 148.3 [21], and mouse anti-StrepII (IBA BioTAGnology, Göttingen, Germany). As organelle makers, rabbit anti-Calreticulin (polyclonal 
IgG fraction; Sigma-Aldrich, Steinheim, Germany), antiERGIC-53 (Sigma-Aldrich), and anti-GM130 (Golgi; EP892Y; Abcam) were used. Detection of the primary antibodies was done with donkey anti-mouse-Alexa488 (Invitrogen), goat anti-rabbit-Cy3 (Dianova, Hamburg, Germany), and, for simultaneous detection of GFP and StrepII together with organelle marker, goat anti-mouseAlexa633 (Invitrogen). For immunoblotting, anti-myc 4A6, anti-HA HA-7, anti-SRP54 (BD Bioscience), anti-MHC I hc HC10 [22] and mAb 7F6, raised against amino acids ${ }_{21}$ GPAVIECWFVEDASGKG $_{35}$ of human tapasin, were used.

Membrane preparation and carbonate extraction

Membranes were prepared from $5 \times 10^{6}$ transiently transfected HeLa cells. The cell pellet was mixed with $50 \mathrm{mM}$ ice-cold Tris buffer ( $\mathrm{pH} 7.3$ ) containing $250 \mathrm{mM}$ sucrose and protease inhibitor mix (Serva, Heidelberg, Germany). Cells were pulped with a glass homogenizer. Post-nuclear supernatants were collected by centrifugation for $10 \mathrm{~min}$ at $700 \mathrm{~g}$ and membranes were sedimented by centrifugation at $100,000 \mathrm{~g}$ for $30 \mathrm{~min}$ at $4{ }^{\circ} \mathrm{C}$. Membranes were resuspended in $0.1 \mathrm{M} \mathrm{Na}_{2} \mathrm{CO}_{3}$ buffer $\mathrm{pH} 11.5$ and incubated on ice for $15 \mathrm{~min}$, followed by centrifugation at $100,000 \mathrm{~g}$ for $20 \mathrm{~min}$ at $4{ }^{\circ} \mathrm{C}$. The supernatant was collected. The remaining pellet was resuspended in carbonate buffer $\mathrm{pH} 11.5$, adjusted to $1.6 \mathrm{M}$ sucrose and overlaid with $1.25 \mathrm{M}$ and $0.25 \mathrm{M}$ sucrose in the same buffer. Centrifugation was performed for $90 \mathrm{~min}$ at $100,000 \mathrm{~g}$ and the floating membranes were collected. Proteins were precipitated by chloroform-methanol and subsequently analyzed by SDS-PAGE (15\%).

Immunofluorescence and image processing

Transiently transfected HeLa cells grown on cover slips were fixed 30 min with $4 \%$ formaldehyde in PBS at room temperature, quenched with $50 \mathrm{mM}$ glycine for $10 \mathrm{~min}$, and permeabilized with $0.1 \%$ Triton X-100 for $20 \mathrm{~min}$. After blocking with $5 \%$ bovine serum albumin for $30 \mathrm{~min}$, cells were stained with the primary antibodies followed by secondary antibodies for $1 \mathrm{~h}$ at room temperature. Nuclei were visualized by DAPI staining (Dianova). Preparations were mounted in $10 \%$ (w/v) Mowiol (Calbiochem/Merck, Nottingham, UK). Samples were analyzed with a confocal laser-scanning microscope (LSM 510; Zeiss, Germany) equipped with a Plan-Apochromat 63x/1.4 Oil DIC objective. Deconvolution of the images was performed using non-blind 2D deconvolution of AutoQuantX2 (MediaCybernetics, Bethesda, MD, USA). Non-transfected cells were removed from the picture prior to determination of Pearson's coefficients, and a threshold was manually set to remove background. For colocalization analysis, the
JACoP plug-in [23] for ImageJ was used to calculate Pearson's coefficients out of 8-10 individual cells per construct and organelle marker. For coreTAP1 and coreTAP2 co-expression, Pearson's coefficients were calculated for coreTAP1-GFP and the organelle marker.

\section{Coimmunoprecipitation}

For coimmunoprecipitation, sheep anti-mouse Dynabeads (Invitrogen) were loaded with mouse anti-myc 4A6 $\left(\mathrm{TMD}_{0}^{\mathrm{TAP} 1}\right.$ and $\mathrm{Tsn}-\mathrm{TMD}_{0}^{\mathrm{TAP} 1}$ ) or mouse anti-HA HA-7 $\left(\mathrm{TMD}_{0}^{\mathrm{TAP} 2}\right.$ and $\mathrm{Tsn}-\mathrm{TMD}_{0}^{\mathrm{TAP} 2}$ ) for $2 \mathrm{~h}$ at $4{ }^{\circ} \mathrm{C}$. Control precipitations were performed using a non-specific isotypematched mouse antibody. After coating, the beads were washed three times with $1 \mathrm{ml}$ IP buffer containing $20 \mathrm{mM}$ Tris/ $\mathrm{HCl}, \mathrm{pH} 7.4,0.1 \% \mathrm{BSA}, 150 \mathrm{mM} \mathrm{NaCl}$, and $5 \mathrm{mM}$ $\mathrm{MgCl}_{2}$. For each sample, $2.5 \times 10^{6} \mathrm{HeLa}$ cells were plated in a $14.5-\mathrm{cm}$ dish the day before the transfection. Then, $24 \mathrm{~h}\left(\mathrm{Tsn}-\mathrm{TMD}_{0} \mathrm{~s}\right)$ or $48 \mathrm{~h}\left(\mathrm{TMD}_{0} \mathrm{~s}\right)$ after transfection, the cells were harvested and solubilized in $1 \mathrm{ml}$ buffer containing $20 \mathrm{mM}$ Tris/ $\mathrm{HCl}, \mathrm{pH} 7.4,150 \mathrm{mM} \mathrm{NaCl}, 5 \mathrm{mM}$ $\mathrm{MgCl}_{2}, 1 \%$ digitonin, and $1 \%$ protease inhibitor mix (Serva) for $1 \mathrm{~h}$ at $4{ }^{\circ} \mathrm{C}$. Solubilized cells were centrifuged for $30 \mathrm{~min}$ at $100,000 \mathrm{~g}$ at $4{ }^{\circ} \mathrm{C}$. After pre-clearing, the supernatant was incubated with pre-coated magnetic beads for $1 \mathrm{~h}$ at $4{ }^{\circ} \mathrm{C}$. After washing, beads were isolated by a magnet and bound protein was eluted with $30 \mu \mathrm{l}$ SDS sample buffer for $10 \mathrm{~min}$ at $65^{\circ} \mathrm{C}$. Eluates were analyzed by SDS-PAGE and subsequent immunoblotting.

\section{Protease $\mathrm{K}$ digestion}

Membranes were prepared as described above. After centrifugation at $100,000 \mathrm{~g}$, membranes were resuspended in icecold PBS containing $5 \mathrm{mM} \mathrm{CaCl} 2$. Proteinase $\mathrm{K}$ (0.6 units, Sigma Aldrich) were added in the absence or presence of $0.1 \%$ Triton-X 100, and incubated on ice for $30 \mathrm{~min}$. Digestion was stopped by the addition of PMSF ( $5 \mathrm{mM}$ final), followed by incubation at $95{ }^{\circ} \mathrm{C}$ for $10 \mathrm{~min}$ in SDS sample buffer. Samples were separated by SDS-PAGE (10\%) and subsequent immunoblotting with the indicated antibodies.

\section{Results}

Expression and membrane insertion of the isolated $\mathrm{TMD}_{0} \mathrm{~s}$

The coreTAP subunits can be expressed without affecting membrane targeting, insertion, folding, dimerization, and transport activity [16]. However, it remains open whether the unique and extra $\mathrm{TMD}_{0}$ represents an autonomous domain with the ability to fold independently of coreTAP 


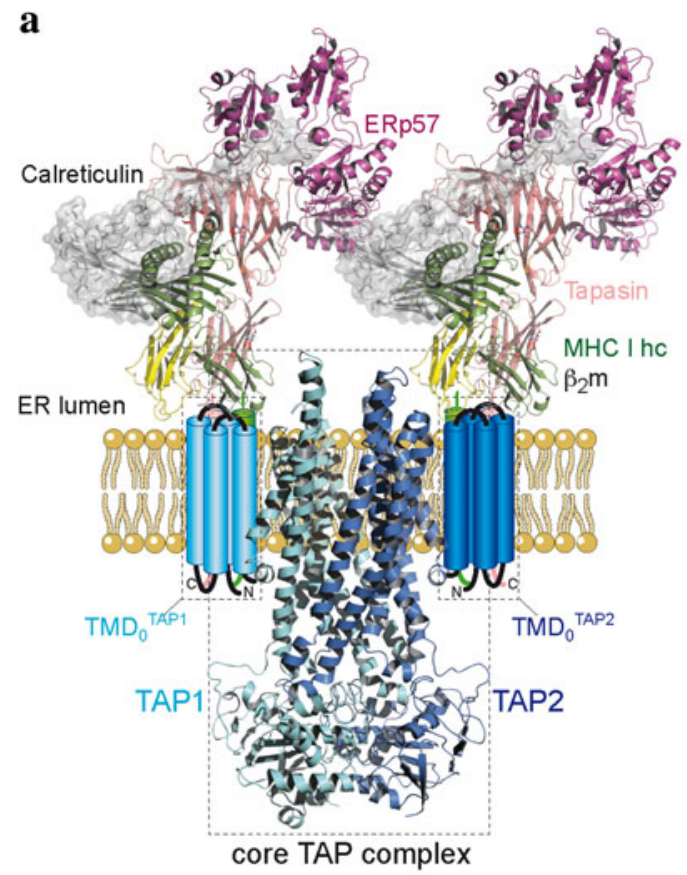

Fig. 1 Unique N-terminal domains $\left(\mathrm{TMD}_{0} \mathrm{~s}\right)$ of TAP1 and TAP2 represent an autonomous membrane protein fold. a Structural model of the TAP complex $[3,11,50]$. CoreTAP is shown as a homology model based on the structure of Sav1866 [13, 15]. The extra $\mathrm{N}$-terminal domain $\mathrm{TMD}_{0}$ of each TAP subunit, illustrated as a fourhelix bundle, recruits the tapasin-ERp57 conjugate via transmembrane domain interaction. b $\mathrm{TMD}_{0}^{\mathrm{TAP} 1}$ and $\mathrm{TMD}_{0}^{\mathrm{TAP} 2}$ are integral

and other components of the peptide-loading complex. We thus divided human TAP1 and TAP2 into $\mathrm{TMD}_{0}$ and coreTAP to further study their functions (Fig. 1a). The boundary for dissection of the domains lies within the second cytoplasmic loop, resulting in $\mathrm{TMD}_{0}^{\mathrm{TAP} 1}$ (aa 1-164) and $\mathrm{TMD}_{0}^{\mathrm{TAP} 2}$ (aa 1-127). For immunodetection, the $\mathrm{TMD}_{0} \mathrm{~s}$ of TAP1 and TAP2 were tagged with a C-terminal myc- and HA-epitope, respectively (Fig. 1b). Strikingly, both $\mathrm{TMD}_{0} \mathrm{~s}$ were expressed at high levels in transiently transfected HeLa cells. $\mathrm{TMD}_{0}^{\mathrm{TAP} 1}$ as well as $\mathrm{TMD}_{0}^{\mathrm{TAP} 2}$ were found to be in the membrane fraction (20 and $16 \mathrm{kDa}$, respectively) together with the integral type I membrane protein tapasin and resistant to alkaline extraction, whereas the peripheral membrane protein, the signal recognition particle SRP54, is in the supernatant (Fig. 1b). These results demonstrate that the $\mathrm{TMD}_{0}$ of each TAP subunit is targeted and inserted as integral membrane proteins.

\section{Subcellular localization of the TAP domains}

The ER is the major compartment for MHC I peptide loading, although TAP activity was also found in post-ER compartments [24]. We therefore investigated the subcellular localization of the N-terminal domains. HeLa cells were transiently transfected with each $\mathrm{TMD}_{0}$ or wt TAP
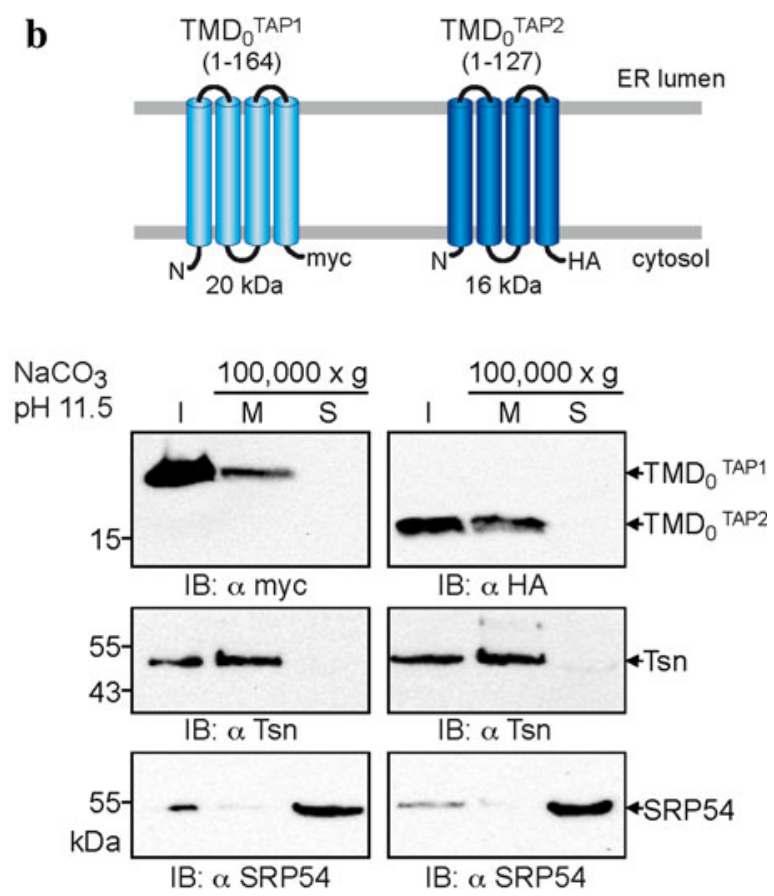

membrane domains. Membranes were prepared from transiently transfected HeLa cells and alkaline extraction was performed. $I$ an aliquot (1/10) of the membranes before alkaline extraction to confirm expression, $M$ and $S$ membrane fraction and supernatant after treatment with carbonate buffer $\mathrm{pH} 11.5$, respectively. Immunoblots were developed against $\mathrm{TMD}_{0}^{\mathrm{TAP} 1 / 2}$, tapasin as integral type I membrane protein, and SRP54 as peripheral membrane protein

and analyzed by immunofluorescence microscopy (Fig. 2). As expected, wt TAP was found to be mostly in the ER. Both $\mathrm{TMD}_{0}^{\mathrm{TAP} 1}$ and $\mathrm{TMD}_{0}^{\mathrm{TAP} 2}$ co-localized to a large extent with the ER. Minor fractions of both $\mathrm{TMD}_{0} \mathrm{~s}$ were found in the ERGIC. Interestingly, the overlap with the ERGIC was more pronounced for $\mathrm{TMD}_{0}^{\mathrm{TAP} 2}$ than for $\mathrm{TMD}_{0}^{\mathrm{TAP} 1}$. The colocalization with the Golgi marker GM130 was only weak, demonstrating that isolated $\mathrm{TMD}_{0} \mathrm{~s}$ are efficiently retained in the early secretory pathway.

We next investigated the localization of coreTAP. Previous studies demonstrated the peptide transport activity of the coreTAP complex into ER-derived microsomes from Sf9 cells using a glycosylation dependent assay [16]. Due to differences in the post-translational modifications between the insect cell and mammalian cell system, this evidence for ER retention of the coreTAP complex might not necessarily be transferrable to human cells. To clarify this point, coreTAP1 and coreTAP2 were fused C-terminally to eGFP and mCerulean, respectively. Confocal laser scanning microscopy directly visualized coreTAP1-eGFP, whereas coreTAP2 was indirectly detected via its C-terminal Strep-tag, due to its low expression level and the relatively weak fluorescence of the mCerulean. Similar to the $\mathrm{TMD}_{0} \mathrm{~s}$, coreTAP1 and coreTAP2 localized to the ER when expressed individually in HeLa cells (Fig. 3a, b). 

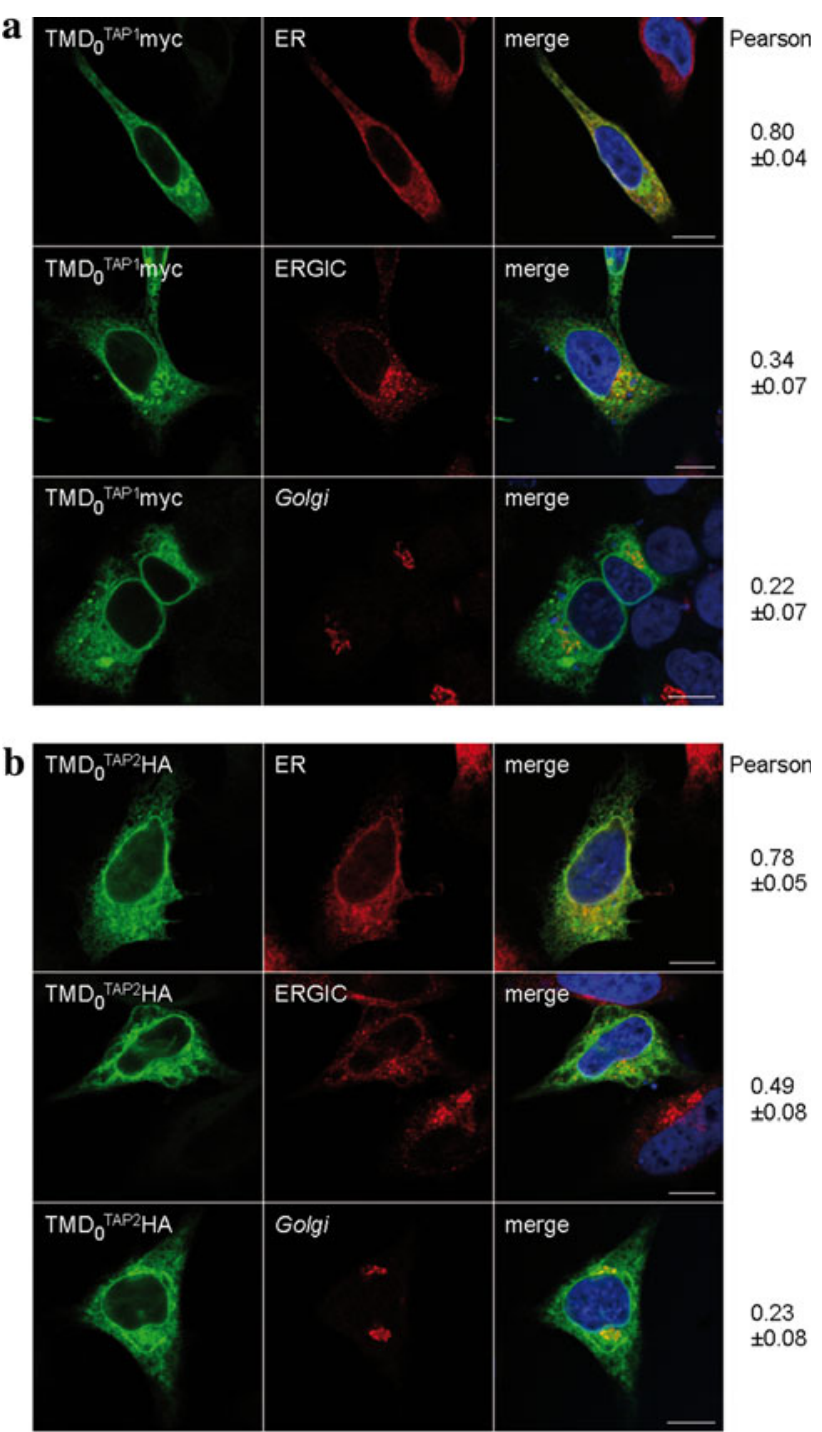

c

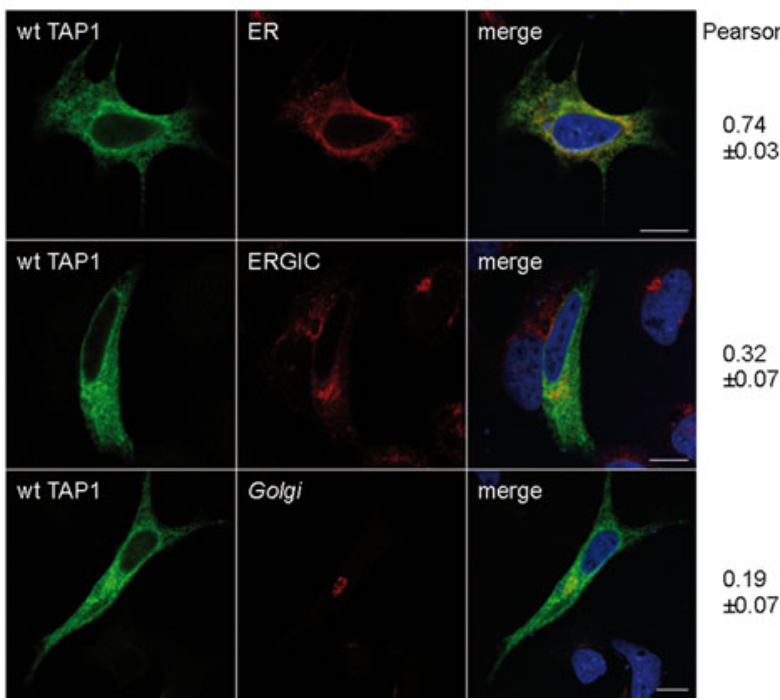

4 Fig. 2 Subcellular localization of $\mathrm{TMD}_{0}^{\mathrm{TAP} 1 / 2}$. Indirect immunofluorescence on transiently transfected HeLa cells $\left(\mathrm{TMD}_{0} \mathrm{~s}\right.$ or wt TAP1/2 as a control) was performed using $\mathrm{TMD}_{0}^{\mathrm{TAP} 1}, \mathrm{TMD}_{0}^{\mathrm{TAP} 2}$ and TAP1 specific (myc, HA and 148.3, respectively, green) as well as organelle specific antibodies [ER anti-calreticulin; ER-Golgi intermediate compartment (ERGIC): ERGIC-53; Golgi GM-130; red]. a TMD ${ }_{0}^{\mathrm{TAP} 1}$, b $\mathrm{TMD}_{0}^{\mathrm{TAP} 2}$, c wt TAP. Images were taken using confocal laser scanning microscopy. Pearson coefficients were calculated from $8-10$ individual images. Scale bar $10 \mu \mathrm{m}$

We reasoned that this ER localization might be caused by the formation of heterodimers with endogenous TAP. To examine if heterodimers of both coreTAP subunits were also restricted to the ER, we coexpressed coreTAP1 and coreTAP2 (Fig. 3c). The Pearson's coefficients for the tested compartments were similar to those of overexpressed wt TAP (Fig. 2c), indicating that the coreTAP shows the same subcellular distribution as wt TAP.

$\mathrm{TMD}_{0} \mathrm{~s}$ of TAP1 and TAP2 form autonomous platforms for tapasin recruitment

It has been previously demonstrated that the coreTAP complex does not interact with tapasin [16, 17, 25]. Thus, the tapasin-binding site could be formed at the interface of $\mathrm{TMD}_{0}$ and coreTAP, or by the $\mathrm{TMD}_{0}$ alone. To distinguish between these possibilities, coimmunoprecipitation experiments were performed with the $\mathrm{TMD}_{0} \mathrm{~s}$ of both TAP subunits and endogenous tapasin in HeLa cells. $\mathrm{TMD}_{0}^{\mathrm{TAP} 1}$ and $\mathrm{TMD}_{0}^{\mathrm{TAP} 2}$ were precipitated using anti-myc or anti-HA antibody, respectively (Fig. 4). Importantly, each $\mathrm{TMD}_{0}$ interacts with tapasin, confirming that the $\mathrm{TMD}_{0} \mathrm{~s}$ are correctly folded and form an independent interaction domain for tapasin.

$\mathrm{TMD}_{0} \mathrm{~s}$ of TAP1 and TAP2 localize to the ER independently of tapasin

$\mathrm{TMD}_{0}^{\mathrm{TAP} 1}$ and $\mathrm{TMD}_{0}^{\mathrm{TAP} 2}$ lack any known ER retention signal but interact with tapasin, which harbors a di-lysine ER retrieval signal [26]. We therefore asked whether binding to tapasin retains the $\mathrm{TMD}_{0}$ in the ER. To address this, we expressed wt TAP or the $\mathrm{TMD}_{0} \mathrm{~s}$ in the tapasindeficient cell line M553 [19, 20] and analyzed their subcellular distribution by immunostaining (Fig. 5). Similar to HeLa cells, wt TAP co-localized with the ER marker and only a minimal fraction was found in the ERGIC and Golgi. The same distribution was observed for $\mathrm{TMD}_{0}^{\mathrm{TAP} 1}$ and $\mathrm{TMD}_{0}^{\mathrm{TAP} 2}$, demonstrating that tapasin interaction is expendable for correct localization. Again, the fraction of $\mathrm{TMD}_{0}^{\mathrm{TAP} 2}$ that was found in the ERGIC was enhanced compared to that of $\mathrm{TMD}_{0}^{\mathrm{TAP}}$. 
Fig. 3 Subcellular localization of coreTAP. HeLa cells were transiently transfected with coreTAP1-eGFP (a), coreTAP2mCerulean $(\mathbf{b})$, or a

combination of both coreTAP constructs (c), and analyzed by confocal laser scanning microscopy. CoreTAP2mCerulean was indirectly visualized via its $\mathrm{C}$-terminal StrepII-tag with a StrepII antibody. Organelles were stained with antibodies against marker proteins $[E R$ anticalreticulin; ER-Golgi intermediate compartment (ERGIC): anti-ERGIC-53; Golgi: anti-GM130]. Pearson coefficients were calculated from 8 to 10 individual images. Scale bar $10 \mu \mathrm{m}$ a

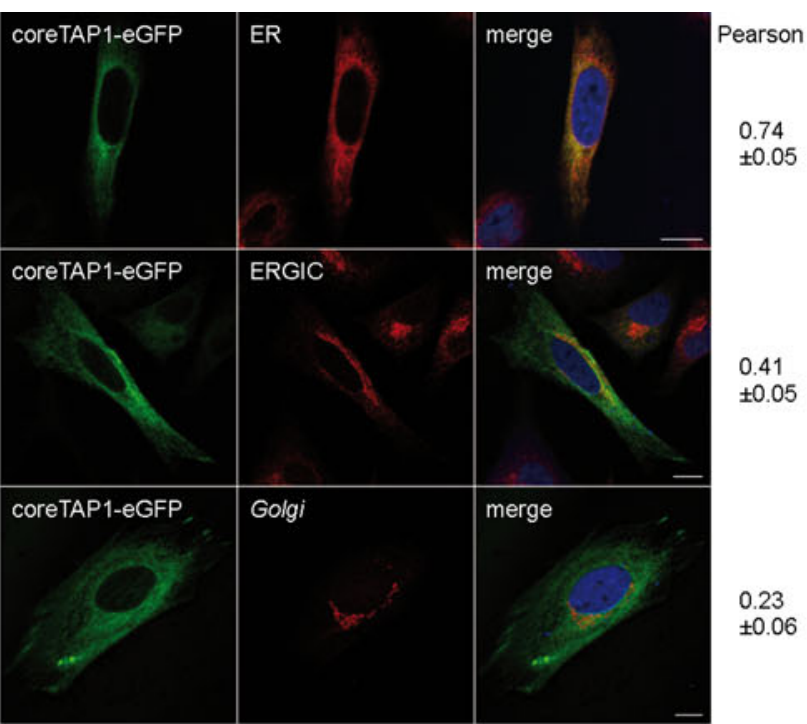

b
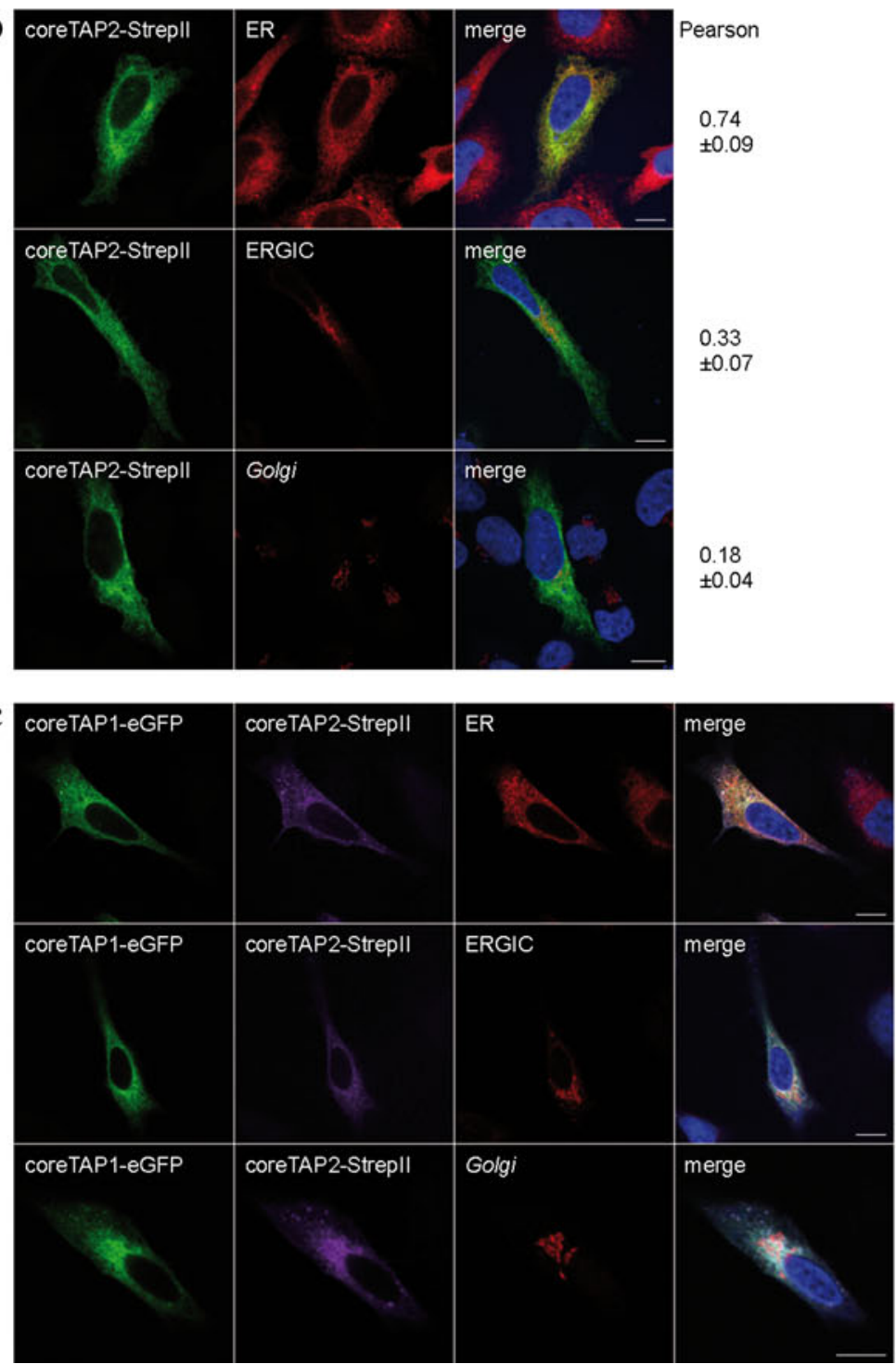

Pearson

0.72

$\pm 0.04$

0.37

$\pm 0.13$

0.25

$\pm 0.07$ 

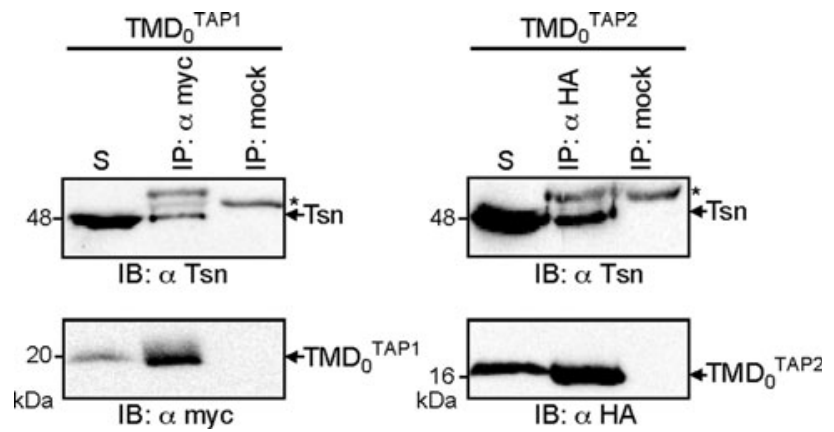

Fig. 4 Recruitment of tapasin by $\mathrm{TMD}_{0}^{\mathrm{TAP} 1 / 2}$. $\mathrm{TMD}_{0}^{\mathrm{TAP} 1}$ or $\mathrm{TMD}_{0}^{\mathrm{TAP} 2}$ were transiently expressed in HeLa cells and subjected to coimmunoprecipitation using myc or HA antibodies. As mock control, an isotype antibody was used. For both $\mathrm{TMD}_{0} \mathrm{~s}$, co-precipitation of tapasin was observed. Asterisks: immunoglobulin heavy chain. The solubilizate $(S)$ represents $1 / 20$ aliquot of the precipitate

Each $\mathrm{TMD}_{0}$ provides one single binding site for tapasin

How many tapasin molecules are present within a fully assembled PLC is still a matter of debate. The tapasin-toTAP ratios reported varied from 1:1 and 2:1 to 4:1 [5,27, 28]. To address this question, we tethered tapasin to the $\mathrm{TMD}_{0}$ of each TAP subunit via a flexible glycine-serine linker of 34 aa, leading to Tsn-TMD ${ }_{0}^{\text {TAP1 }}$ and Tsn$\mathrm{TMD}_{0}^{\mathrm{TAP} 2}$. As a result, the stoichiometry is fixed and one tapasin binding site is already occupied by the fused tapasin (Fig. 6a). Similar to the isolated $\mathrm{TMD}_{0}$ s, the fusion constructs are located to the ER in HeLa cells, after transient expression (data not shown). Our recent experiments targeting the topology of TAP2 revealed that the N-terminus of TAP2 faces the cytosol. For further clarification, the membrane topology of the fusion constructs was confirmed by Proteinase K treatment (Fig. 6b). The myc- or HA-tag at C-terminus of $\mathrm{Tsn}^{-\mathrm{TMD}_{0}}$ was accessible from the cytosol, where the ER-lumenal calreticulin is degraded only after Triton-X 100 permeabilization of the membrane. In addition, the linker is accessible for Proteinase $\mathrm{K}$, cleaving the tapasin from $\mathrm{TMD}_{0}$. These results demonstrate the correct membrane insertion of tapasin and that the linker and C-terminus of $\mathrm{TMD}_{0} \mathrm{~s}$ are exposed to the cytosol. By coimmunoprecipitation, we could demonstrate that no additional, endogenous tapasin was recruited to Tsn$\mathrm{TMD}_{0}^{\mathrm{TAP} 1}$ or Tsn-TMD $0{ }^{\mathrm{TAP} 2}$ (Fig. 6c), revealing that there

Fig. 5 Subcellular localization of $\mathrm{TMD}_{0}^{\mathrm{TAP} 1}$ and $\mathrm{TMD}_{0}^{\mathrm{TAP} 2}$ in tapasin deficient cells. $\mathrm{TMD}_{0}^{\mathrm{TAP} 1}(\mathbf{a}), \mathrm{TMD}_{0}^{\mathrm{TAP} 2}(\mathbf{b})$, and wt TAP1/2 (c) were transiently expressed in the tapasin deficient cell line M553, stained with the antibodies as indicated in Fig. 2, and analyzed via indirect immunofluorescence. Organelles were stained with antibodies against marker proteins [ER anti-calreticulin; ER-Golgi intermediate compartment (ERGIC): anti-ERGIC-53; Golgi: anti-GM130]. Pearson coefficients were calculated from 8 to 10 individual images. Scale bar $10 \mu \mathrm{m}$
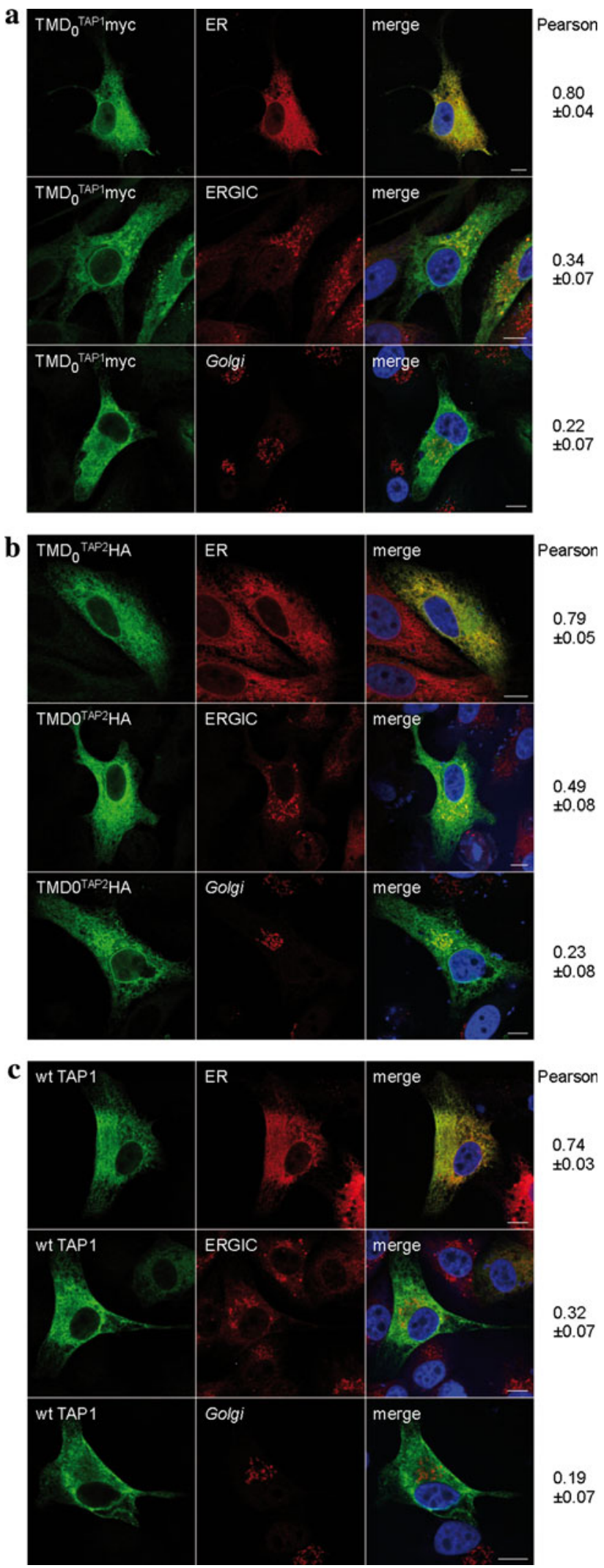

is only one single binding site for tapasin on each $\mathrm{TMD}_{0}$. Although Tsn-TMD ${ }_{0}^{\text {TAP1 }}$ recruited slightly less of MHC I than $\mathrm{Tsn}-\mathrm{TMD}_{0}^{\mathrm{TAP} 2}$, both $\mathrm{Tsn}-\mathrm{TMD}_{0}$ fusion proteins were 
Fig. 6 Each $\mathrm{TMD}_{0}$ harbors one single tapasin-binding site. a Model of the Tsn-TMD ${ }_{0}^{\mathrm{TAP} 1 / 2}$ fusion constructs interacting with MHC I molecules. b Membrane topology of the Tsn-TMD ${ }_{0}^{\text {TAP } 1 / 2}$ fusion constructs. Crude membranes were prepared from HeLa cells transiently transfected with Tsn$\mathrm{TMD}_{0}^{\mathrm{TAP} 1}$ or Tsn-TMD ${ }_{0}^{\mathrm{TAP} 2}$.

Membranes (Membr.) were treated with Proteinase K $(0.6$ units) in the absence or presence of Triton-X 100 (T-X 100) for $30 \mathrm{~min}$ on ice followed by immunoblotting. c Tsn$\mathrm{TMD}_{0}^{\mathrm{TAP} 1}$ or Tsn-TMD ${ }_{0}^{\mathrm{TAP} 2}$ were transiently expressed in HeLa cells and subjected to coimmunoprecipitation with anti-myc, anti-HA, or an isotype control antibody. Asterisks: immunoglobulin heavy chain. The solubilizate $(S)$ represents $1 / 20$ aliquot of the precipitate $\mathbf{a}$

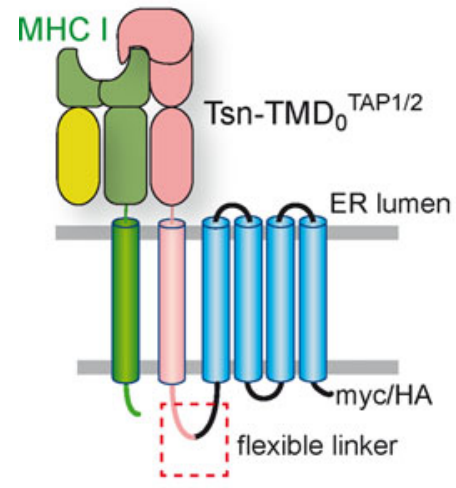

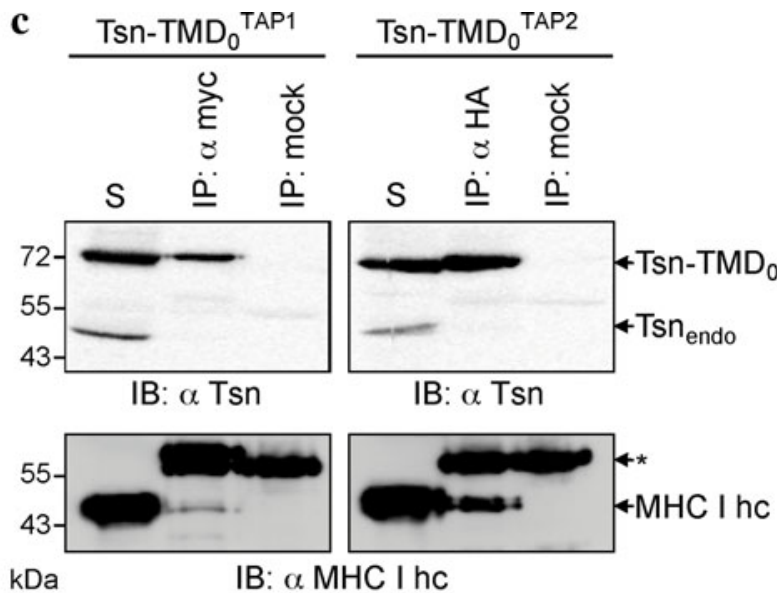

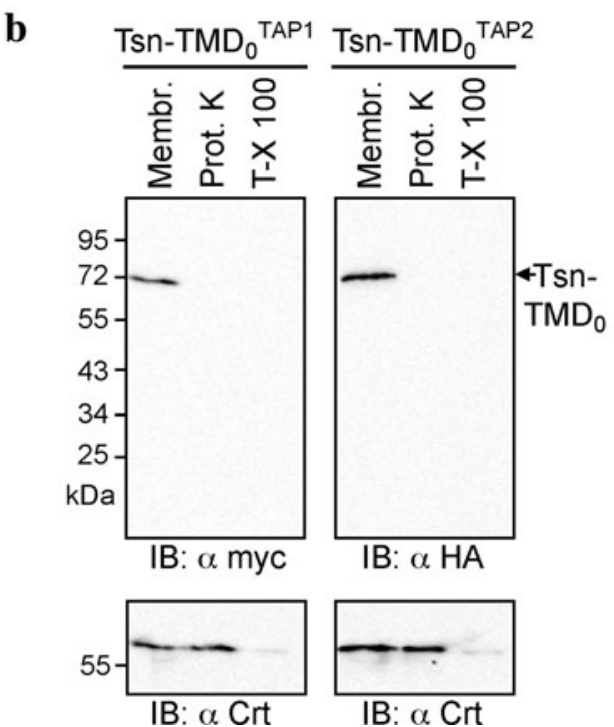

able to bind MHC I, showing that the fused tapasin is folded and functional.

\section{Discussion}

In this study, we demonstrated that the isolated $\mathrm{TMD}_{0} \mathrm{~s}$ of TAP1 and TAP2 are independently targeted to the ER membrane and form autonomous interaction hubs for tapasin recruitment. They are not required for the ER localization and transport function of the coreTAP complex [16]. A similar functional partition into a core $\mathrm{ABC}$ transport complex and extra N-terminal domains was shown for other ABC transporters. Some of these N-terminal extensions have an impact on the subcellular trafficking or function of the ABC transporter, while others seem to serve different purposes, extending the fascinating properties of $\mathrm{ABC}$ transporters towards receptor and channel functions. The lysosomal polypeptide transporter ABCB9 (TAP-like), which forms a homodimeric complex, possesses a $\mathrm{TMD}_{0}$ that can be expressed separately. Although this $\mathrm{TMD}_{0}$ is dispensable for mere transport activity, it is required for the lysosomal localization of the transporter. The core transport complex lacking the $\mathrm{TMD}_{0} \mathrm{~s}$ is targeted to the plasma membrane but redirected into lysosomes upon separate expression of $\mathrm{TMD}_{0}$ [29]. However, an intrinsic affinity of $\mathrm{TMD}_{0}$ for the core translocation complex, as seen for ABCB9, was not observed for TAP (data not shown).

Mitochondrial ABC transporters, also members of the ABCB family, have N-terminal extensions containing very long mitochondrial pre-sequences [30-32]. In contrast to non-mitochondrial $\mathrm{ABC}$ transporters, these N-terminal extensions are not membrane spanning per se. Nevertheless, they are essential for correct targeting, since deletion of the leader sequence in ABCB 10 and its yeast homologue MDL1 resulted in mistargeting of the transporter to the ER membrane [31, 32]. Vice versa, fusion of the N-terminal extension of ABCB7 (residue 1-135) to the dihydrofolate reductase leads to mitochondrial targeting of the fusion protein [30]. 
Most full-length $\mathrm{ABC}$ transporters of the subfamily $\mathrm{C}$ also display an extra N-terminal domain (named MSD or $\mathrm{TMD}_{0}$ ), which typically comprises five transmembranespanning segments (reviewed in [33]). MRP1 and MRP2, for example, harbor $\mathrm{TMD}_{0} \mathrm{~s}$ with strategic functions in targeting of the transporters to the plasma membrane [34, 35]. As for TAP, the $\mathrm{TMD}_{0}$ of MRP1 is dispensable for transport activity per se [36]. The sulfonylurea receptor SUR1 (ABCC8) is the regulatory subunit of the $\mathrm{K}_{\mathrm{ATP}}$ channel $\mathrm{K}_{\mathrm{IR}}$ 6.2. Mutations in $\mathrm{K}_{\mathrm{IR}} 6.2$ are associated with congenital hyperinsulinism [37, 38] and neonatal diabetes $[39,40]$. TMD ${ }_{0}^{\text {SUR1 }}$ is the interaction and regulation domain to $\mathrm{K}_{\mathrm{IR}} 6.2[41,42]$. The $\mathrm{TMD}_{0}^{\mathrm{SUR} 1}$, expressed in the absence of the remaining core $\mathrm{ABC}$ transporter, retains its ability to associate with and gate $\mathrm{K}_{\mathrm{IR}} 6.2$ [43]. In conclusion, some $\mathrm{ABC}$ transporters present an interesting division of work using several independent membrane-spanning domains: one forming the gated translocation pathway and one with functions in regulation, trafficking, or binding of interaction partners. However, the $\mathrm{TMD}_{0} \mathrm{~s}$ of TAP1 and TAP2 constitute prime examples of ER-resident $\mathrm{ABC}$ proteins.

A number of mechanisms are known that retain or retrieve proteins in or to the ER. Soluble proteins are retrieved from post-ER compartments by the KDEL motif that binds to the KDEL receptor. For type I membrane proteins, C-terminal di-lysine motifs (KKxx or KxKxx) interact with COPI vesicles for retrieval to the ER [44]. Type II membrane proteins are retained by a double-arginine motif at the N-terminus [45]. However, neither coreTAP nor any of the $\mathrm{TMD}_{0} \mathrm{~s}$ contain these characteristic signals. Nevertheless, direct evidence for ER localization of both $\mathrm{TMD}_{0} \mathrm{~s}$ is delivered in this work by immunofluorescence analysis. $\mathrm{TMD}_{0}^{\mathrm{TAP} 1}$ and $\mathrm{TMD}_{0}^{\mathrm{TAP} 2}$ were predominantly found in the ER, with a minor fraction entering the post-ER compartment, ERGIC. This distribution resembles that of wt TAP and is in agreement with a previous study that found a minor fraction of TAP active in the ERGIC [24]. Of note, the escape of $\mathrm{TMD}_{0}^{\mathrm{TAP} 2}$ into the ERGIC is enhanced compared to $\mathrm{TMD}_{0}^{\mathrm{TAP} 1}$. These data imply that the $\mathrm{TMD}_{0} \mathrm{~s}$ of both TAP subunits are retained in the ER, but the unidentified retention or retrieval factor acts more strongly in $\mathrm{TMD}_{0}^{\mathrm{TAP} 1}$ than in $\mathrm{TMD}_{0}^{\mathrm{TAP} 2}$. This retention/retrieval signal must be directly located within each $\mathrm{TMD}_{0}$, because ER localization is not mediated by the interaction with the KKxx motif-containing partner tapasin. The localization of wt TAP was formerly suggested to be independent of tapasin [24]. Here, we demonstrate that this is also the case for the isolated membrane interaction hubs $\mathrm{TMD}_{0}$ of TAP1 and TAP2. In addition, we provide direct evidence that coreTAP1 and coreTAP2 localize to the ER membrane. Escape to post-ER compartments was weak and comparable to that of full-length TAP, demonstrating that the mechanism for TAP ER retention is preserved in coreTAP.

The observation that the independently expressed $\mathrm{TMD}_{0} \mathrm{~s}$ of both TAP subunits are able to recruit tapasin gives direct evidence that the $\mathrm{TMD}_{0} \mathrm{~s}$ are folded and functional independent of coreTAP. Furthermore, coimmunoprecipitation experiments with $\mathrm{Tsn}-\mathrm{TMD}_{0}$ fusions demonstrate that each $\mathrm{TMD}_{0}$ only bears one single binding site for tapasin. This suggests a tapasin-to-TAP subunit ratio of $1: 1$, which is in perfect agreement with the latest study on this subject [28]. However, we cannot formally rule out the possibility that a second tapasin-binding site is formed by combination of the very C-terminal parts of $\mathrm{TMD}_{0}^{\mathrm{TAP} 1}$ and $\mathrm{TMD}_{0}^{\mathrm{TAP} 2}$ as well as the $\mathrm{N}$-terminus of coreTAP1 and coreTAP2. Tsn-TMD ${ }_{0}^{\text {TAP1 }}$ was reproducibly found to recruit less MHC I than Tsn-TMD ${ }_{0}^{\mathrm{TAP} 2}$ (Fig. 6). This might reflect a greater importance for $\mathrm{TMD}_{0}^{\mathrm{TAP} 2}$ in MHC I loading. This is a reasonable speculation, since for chicken and all other avian MHC I loci sequenced so far, only TAP2 harbors a $\mathrm{TMD}_{0}$, while TAP1 has no $\mathrm{TMD}_{0}$ and is therefore equivalent to coreTAP1 $[46,47]$. The exact interaction sites of $\mathrm{TMD}_{0}^{\mathrm{TAP} 1}$ and $\mathrm{TMD}_{0}^{\mathrm{TAP} 2}$ for tapasin remain unknown. For tapasin, a number of candidate residues have been proposed, including residues F397, F401, G405, K408, and W412 of mouse tapasin [48], and K408 of human tapasin [49]. For TAP, it was previously shown that removal of the first transmembrane helix destroys the tapasin-TAP interaction [17]. Whether this is due to an altered overall folding of the truncated $\mathrm{N}$-terminal domain or missing essential residues will require future approaches. The structural analysis of the TMD is one approach to resolve this important interaction hub.

In conclusion, we show for the first time that the $\mathrm{TMD}_{0} \mathrm{~s}$ of both TAP subunits form autonomous interaction scaffolds for the assembly of the MHC I peptide-loading complex in the ER membrane. Each $\mathrm{TMD}_{0}$ connects ERp57, calreticulin, and peptide-receptive MHC I via a single tapasin molecule to the peptide supplier TAP. According to this, the PLC can be subdivided into three functional modules: (1) peptide binding and transport by the coreTAP complex, (2) peptide loading and editing by the Tsn-ERp57/MHC I subcomplex, and (3) the conjunction of these functions, accomplished by the interaction hubs $\mathrm{TMD}_{0}^{\mathrm{TAP} 1}$ and $\mathrm{TMD}_{0}^{\mathrm{TAP} 2}$.

Acknowledgments We thank Drs. David Parcej and Andreas Hinz for providing the coreTAP2 constructs. The German Research Foundation (SFB 807 Transport and Communication across Biological Membranes and TA157/7 to R.T.), the European Drug Initiative on Channels and Transporters (EDICT to R.T.) funded by the European Commission Seventh Framework Program, and the Japan Society for the Promotion of Science (JSPS grant 20228001 to K.U.) supported this work. 
Open Access This article is distributed under the terms of the Creative Commons Attribution License which permits any use, distribution, and reproduction in any medium, provided the original author(s) and the source are credited.

\section{References}

1. Neefjes J, Jongsma ML, Paul P, Bakke O (2011) Towards a systems understanding of MHC class I and MHC class II antigen presentation. Nat Rev Immunol 11:823-836

2. Cresswell P (2005) Antigen processing and presentation. Immunol Rev 207:5-7

3. Parcej D, Tampé R (2010) ABC proteins in antigen translocation and viral inhibition. Nat Chem Biol 6:572-580

4. Sadasivan B, Lehner PJ, Ortmann B, Spies T, Cresswell P (1996) Roles for calreticulin and a novel glycoprotein, tapasin, in the interaction of MHC class I molecules with TAP. Immunity 5:103-114

5. Ortmann B, Copeman J, Lehner PJ, Sadasivan B, Herberg JA, Grandea AG, Riddell SR, Tampé R, Spies T, Trowsdale J, Cresswell P (1997) A critical role for tapasin in the assembly and function of multimeric MHC class I-TAP complexes. Science 277:1306-1309

6. Williams AP, Peh CA, Purcell AW, McCluskey J, Elliott T (2002) Optimization of the MHC class I peptide cargo is dependent on tapasin. Immunity 16:509-520

7. Howarth M, Williams A, Tolstrup AB, Elliott T (2004) Tapasin enhances MHC class I peptide presentation according to peptide half-life. Proc Natl Acad Sci USA 101:11737-11742

8. Madden DR (1995) The three-dimensional structure of peptideMHC complexes. Annu Rev Immunol 13:587-622

9. Kozlov G, Maattanen P, Schrag JD, Pollock S, Cygler M, Nagar B, Thomas DY, Gehring K (2006) Crystal structure of the bb' domains of the protein disulfide isomerase ERp57. Structure 14:1331-1339

10. Nørgaard Toft K, Larsen N, Steen Jørgensen F, Højrup P, Houen G, Vestergaard B (2008) Small angle X-ray scattering study of calreticulin reveals conformational plasticity. Biochim Biophys Acta 1784:1265-1270

11. Dong G, Wearsch PA, Peaper DR, Cresswell P, Reinisch KM (2009) Insights into MHC class I peptide loading from the structure of the tapasin-ERp57 thiol oxidoreductase heterodimer. Immunity 30:21-32

12. Chouquet A, Païdassi H, Ling WL, Frachet P, Houen G, Arlaud GJ, Gaboriaud C (2011) X-ray structure of the human calreticulin globular domain reveals a peptide-binding area and suggests a multi-molecular mechanism. PLoS ONE 6:e17886

13. Dawson RJ, Locher KP (2006) Structure of a bacterial multidrug ABC transporter. Nature 443:180-185

14. Gaudet R, Wiley DC (2001) Structure of the ABC ATPase domain of human TAP1, the transporter associated with antigen processing. EMBO J 20:4964-4972

15. Oancea G, O'Mara ML, Bennett WF, Tieleman DP, Abele R, Tampé R (2009) Structural arrangement of the transmission interface in the antigen $\mathrm{ABC}$ transport complex TAP. Proc Natl Acad Sci USA 106:5551-5556

16. Koch J, Guntrum R, Heintke S, Kyritsis C, Tampé R (2004) Functional dissection of the transmembrane domains of the transporter associated with antigen processing (TAP). J Biol Chem 279:10142-10147

17. Koch J, Guntrum R, Tampé R (2006) The first N-terminal transmembrane helix of each subunit of the antigenic peptide transporter TAP is essential for independent tapasin binding. FEBS Lett 580:4091-4096

18. Leonhardt RM, Keusekotten K, Bekpen C, Knittler MR (2005) Critical role for the tapasin-docking site of TAP2 in the functional integrity of the MHC class I-peptide-loading complex. J Immunol 175:5104-5114

19. Cormier JN, Panelli MC, Hackett JA, Bettinotti MP, Mixon A, Wunderlich J, Parker LL, Restifo NP, Ferrone S, Marincola FM (1999) Natural variation of the expression of HLA and endogenous antigen modulates CTL recognition in an in vitro melanoma model. Int J Cancer 80:781-790

20. Marincola FM, Shamamian P, Alexander RB, Gnarra JR, Turetskaya RL, Nedospasov SA, Simonis TB, Taubenberger JK, Yannelli J, Mixon A et al (1994) Loss of HLA haplotype and B locus down-regulation in melanoma cell lines. J Immunol 153:1225-1237

21. Meyer TH, van Endert PM, Uebel S, Ehring B, Tampé R (1994) Functional expression and purification of the $\mathrm{ABC}$ transporter complex associated with antigen processing (TAP) in insect cells. FEBS Lett 351:443-447

22. Stam NJ, Vroom TM, Peters PJ, Pastoors EB, Ploegh HL (1990) HLA-A- and HLA-B-specific monoclonal antibodies reactive with free heavy chains in western blots, in formalin-fixed, paraffin-embedded tissue sections and in cryo-immuno-electron microscopy. Int Immunol 2:113-125

23. Bolte S, Cordelières FP (2006) A guided tour into subcellular colocalization analysis in light microscopy. J Microscopy 224:213-232

24. Ghanem E, Fritzsche S, Al-Balushi M, Hashem J, Ghuneim L, Thomer L, Kalbacher H, van Endert P, Wiertz E, Tampé R, Springer S (2010) The transporter associated with antigen processing (TAP) is active in a post-ER compartment. J Cell Sci 123:4271-4279

25. Procko E, Raghuraman G, Wiley DC, Raghavan M, Gaudet R (2005) Identification of domain boundaries within the N-termini of TAP1 and TAP2 and their importance in tapasin binding and tapasin-mediated increase in peptide loading of MHC class I. Immunol Cell Biol 83:475-482

26. Paulsson KM, Jevon M, Wang JW, Li S, Wang P (2006) The double lysine motif of tapasin is a retrieval signal for retention of unstable MHC class I molecules in the endoplasmic reticulum. J Immunol 176:7482-7488

27. Li S, Sjögren HO, Hellman U, Pettersson RF, Wang P (1997) Cloning and functional characterization of a subunit of the transporter associated with antigen processing. Proc Natl Acad Sci USA 94:8708-8713

28. Rufer E, Leonhardt RM, Knittler MR (2007) Molecular architecture of the TAP-associated MHC class I peptide-loading complex. J Immunol 179:5717-5727

29. Demirel O, Bangert I, Tampé R, Abele R (2010) Tuning the cellular trafficking of the lysosomal peptide transporter TAPL by its N-terminal domain. Traffic 11:383-393

30. Csere P, Lill R, Kispal G (1998) Identification of a human mitochondrial $\mathrm{ABC}$ transporter, the functional orthologue of yeast Atm1p. FEBS Lett 441:266-270

31. Graf SA, Haigh SE, Corson ED, Shirihai OS (2004) Targeting, import, and dimerization of a mammalian mitochondrial ATP binding cassette $(\mathrm{ABC})$ transporter, $\mathrm{ABCB} 10$ (ABC-me). J Biol Chem 279:42954-42963

32. Gompf S, Zutz A, Hofacker M, Haase W, van der Does C, Tampé R (2007) Switching of the homooligomeric ATP-binding cassette transport complex MDL1 from post-translational mitochondrial import to endoplasmic reticulum insertion. FEBS J 274:5298-5310

33. Tusnády GE, Sarkadi B, Simon I, Váradi A (2006) Membrane topology of human ABC proteins. FEBS Lett 580:1017-1022 
34. Westlake CJ, Cole SPC, Deeley RG (2005) Role of the NH2terminal membrane spanning domain of multidrug resistance protein $1 / \mathrm{ABCC} 1$ in protein processing and trafficking. Mol Biol Cell 16:2483-2492

35. Bandler PE, Westlake CJ, Grant CE, Cole SPC, Deeley RG (2008) Identification of regions required for apical membrane localization of human multidrug resistance protein 2. Mol Pharmacol 74:9-19

36. Bakos E, Evers R, Szakács G, Tusnády GE, Welker E, Szabó K, Haas M, van Deemter L, Borst P, Váradi A, Sarkadi B (1998) Functional multidrug resistance protein (MRP1) lacking the N-terminal transmembrane domain. J Biol Chem 273:32167-32175

37. Thomas PM, Cote GJ, Wohllk N, Haddad B, Mathew PM, Rabl W, Aguilar-Bryan L, Gagel RF, Bryan J (1995) Mutations in the sulfonylurea receptor gene in familial persistent hyperinsulinemic hypoglycemia of infancy. Science 268:426-429

38. James C, Kapoor RR, Ismail D, Hussain K (2009) The genetic basis of congenital hyperinsulinism. J Med Genet 46:289-299

39. Bryan J, Munoz A, Zhang X, Dufer M, Drews G, Krippeit-Drews P, Aguilar-Bryan L (2007) ABCC8 and ABCC9: ABC transporters that regulate $\mathrm{K}+$ channels. Pflugers Arch 453:703-718

40. Aittoniemi J, Fotinou C, Craig TJ, de Wet H, Proks P, Ashcroft FM (2009) Review. SUR1: a unique ATP-binding cassette protein that functions as an ion channel regulator. Philos Trans R Soc Lond B 364:257-267

41. Chan KW, Zhang H, Logothetis DE (2003) N-terminal transmembrane domain of the SUR controls trafficking and gating of Kir6 channel subunits. EMBO J 22:3833-3843

42. Gloyn AL, Pearson ER, Antcliff JF, Proks P, Bruining GJ, Slingerland AS, Howard N, Srinivasan S, Silva JMCL, Molnes J, Edghill EL, Frayling TM, Temple IK, Mackay D, Shield JPH, Sumnik Z, van Rhijn A, Wales JKH, Clark P, Gorman S,
Aisenberg J, Ellard S, Njølstad PR, Ashcroft FM, Hattersley AT (2004) Activating mutations in the gene encoding the ATP-sensitive potassium-channel subunit Kir6.2 and permanent neonatal diabetes. New Engl J Med 350:1838-1849

43. Babenko AP, Aguilar-Bryan L, Bryan J (1998) A view of sur/ KIR6.X KATP channels. Annu Rev Physiol 60:667-687

44. Cosson P, Letourneur F (1994) Coatomer interaction with dilysine endoplasmic reticulum retention motifs. Science 263:1629-1631

45. Schutze MP, Peterson PA, Jackson MR (1994) An N-terminal double-arginine motif maintains type II membrane proteins in the endoplasmic reticulum. EMBO J 13:1696-1705

46. Moon DA, Veniamin SM, Parks-Dely JA, Magor KE (2005) The MHC of the duck (Anas platyrhynchos) contains five differentially expressed class I genes. J Immunol 175:6702-6712

47. Walker BA, Hunt LG, Sowa AK, Skjødt K, Göbel TW, Lehner PJ, Kaufman J (2011) The dominantly expressed class I molecule of the chicken MHC is explained by coevolution with the polymorphic peptide transporter (TAP) genes. Proc Natl Acad Sci USA 108:8396-8401

48. Papadopoulos M, Momburg F (2007) Multiple residues in the transmembrane helix and connecting peptide of mouse tapasin stabilize the transporter associated with the antigen-processing TAP2 subunit. J Biol Chem 282:9401-9410

49. Petersen JL, Hickman-Miller HD, Mcllhaney MM, Vargas SE, Purcell AW, Hildebrand WH, Solheim JC (2005) A charged amino acid residue in the transmembrane/cytoplasmic region of tapasin influences MHC class I assembly and maturation. J Immunol 174:962-969

50. Abele R, Tampé R (2009) Peptide trafficking and translocation across membranes in cellular signaling and self-defense strategies. Curr Opin Cell Biol 21:508-515 